\title{
Measuring State Capacity in Contemporary latin AMERICA*
}

\author{
Midiendo la capacidad estatal en la América Latina contemporánea
}

\section{HILLEL DAVID SOIFER}

Temple University

\begin{abstract}
This paper builds a new measure of state capacity for application to contemporary Latin America which improves on existing indices in several ways. First, rather than using a single proxy, it combines multiple dimensions (extraction, security, and the administration of basic services) of the minimal or juridical state. Second, each dimension is measured with multiple indicators, which allows scholars to work around problems of subnational data availability. Third and most centrally, cases are scored using a new, reach-adjusted, population and territory-weighted approach, which provides the first systematic means of assessment of the power of the national state and its uneven reach across territory and into society and thus allows the empirical investigation of a crucial aspect of Latin American stateness.
\end{abstract}

Key words: State capacity, State Power, Measurement, Unevenness, Administration.

\begin{abstract}
RESUMEN
El presente trabajo construye una nueva medida de la capacidad estatal para su aplicación en América Latina que mejora los índices existentes en varios aspectos. En primer lugar, no se utiliza un solo proxy, sino que se combinan múltiples dimensiones (extracción, seguridad, y la administración de servicios básicos) del estado mínimo o jurídico. En segundo lugar, cada dimensión es medida con múltiples indicadores lo que permite a los académicos sortear el obstáculo de la disponibilidad de datos a nivel sub-nacional. En tercer lugar, y lo más importante, los casos son ordenados utilizando un enfoque ajustado por alcance, población y territorio, que ofrece por primera vez una forma sistemática de determinar el poder del Estado nacional y su alcance irregular en un territorio y en la sociedad, permitiendo así la investigación de un aspecto crucial de la estatalidad latinoamericana.
\end{abstract}

Palabras clave: Capacidad estatal, poder del Estado, medida, irregularidad, administración.

* An earlier version of this paper was presented at the 'Stateness in Latin America' conference in Santiago, Chile, March 2012. I'd like to thank (without implicating) participants at the conference and an anonymous reviewer for their comments and Kevin Arceneaux for a helpful email exchange. This article is part of the Millenium Nucleus for the Study of Stateness and Democracy in Latin America, Project NS100014, of the Ministry of Economy and Tourism of Chile. I would like to thank the financial support of FONDECYT (project 1110565). 
This paper proposes a conceptualization and measurement of state capacity to be applied to the study of contemporary Latin America. Building on a broad consensus in the state capacity literature, I disaggregate the concept into three necessary constituent dimensions-security, extraction, and administration. I develop a measurement scheme for these dimensions of capacity that captures the uneven reach of the state across society and territory.

My goal is to build a measurement scheme for what Michael Mann (1984) called 'infrastructural power': the ability of the state to effectively exercise authority and implement policy throughout its national territory. Most scholarship on state capacity, strength, and power studies something closely akin to Mann's concept, which has been central to the study of the state. ${ }^{1}$ Yet we lack a satisfying conceptualization and measurement scheme for this concept. This paper attempts to fill that important gap in our analytical toolkit. To do so, I begin by laying some analytical groundwork in terms of definitional and measurement choices. I then use that groundwork to discuss the limitations of existing measurement schemes, highlighting the novelty of the one proposed in this paper. The third section develops what I call a 'reach-adjusted' measure of state capacity, and I conclude with some preliminary thoughts about how this measure might fruitfully be combined with measures of other dimensions of the broader concept of 'stateness.'

\section{CONCEPTUAL CHOICES}

In designing a scheme to measure state capacity, we must begin by making some decisions about the definition of that concept. I defend in this section the value of focusing on a narrow, basic scope of state functions, and of incorporating into the definition the state's spatial and societal reach.

\section{National and Local States}

With the vogue of decentralization in the developing world, and the prominence of federal systems among Latin American countries, many citizens' experiences with the state are with subnational levels of government. Yet even with this shift (and the rise of globalization) national political units are still the dominant form of political authority and allegiance. I therefore opt in the measurement scheme developed below to set aside the question of which aspects of the state are formally provided by certain levels of government to focus on the extent of political authority present in a given country. One might fruitfully adapt the measurement scheme developed here for comparison across sub-national units; my focus is on developing a strategy for crossnational comparison. 


\section{The Minimal State}

I suggest the need to develop a definition of stateness that is limited in scope, rather than including in our definition social service provision, economic regulation, or state intervention. Including those more demanding dimensions would lump together a fairly capable but minimal state (for example, Chile) with a fairly weak state. ${ }^{2}$ In the aftermath of the neoliberal turn in Latin America, which has led to a retrenchment of state intervention and bureaucracy, we should be concerned to avoid such conflation of minimal states with those that are fundamentally weak. Therefore, I develop a conceptualization scheme that carefully evaluates various elements of the capacity of the minimal/juridical state.

Another reason to develop a measurement scheme around a fairly simple conceptualization of the state is to avoid the problem of conflating causal and constitutive relationships. We should avoid developing a measurement scheme that relies on the outcomes of any state program to measure state capacity, since that presumes a direct link (and not just a correlation) between outputs and outcomes. ${ }^{3}$ We should also avoid using the nature of state institutions as an indicator for state strength -while, for example, Lange (2009) claims strong evidence that direct rule is associated with state strength in colonial Africa, we should not use direct rule as a measure of state strength- if we do so, we lose the ability to revisit Lange's claims in the Latin American context. Thus, I build a definition that seeks to minimize reliance on causes or outcomes of state strength as indicators of it - though, of course, this cannot be completely avoided.

\section{The Spatial Dimension}

As Guillermo O'Donnell (1993) first pointed out, the Latin American state's reach is spatially uneven within a given territory. Thus, the assumption that the state is equally present everywhere is flawed. Many countries (indeed, nearly every country in Latin America) has some regions where the state is effective, and others to which its authority does not extend. ${ }^{4}$ This spatially uneven nature of state power has been shown to be consequential for a variety of outcomes of interest, including the emergence of insurgency (Goodwin, 1999) and the location of drug production and refinement (Thoumi, 1995). ${ }^{5}$

2 See Fukuyama (2004) for the distinction between scope and strength. The analytical move I make here is analogous to that made by scholars in defending a procedural rather than substantive definition of democracy. (See for example Bowman et. al., 2005)

3 Thus, although I find very useful Yashar's (2005: 6) claim that state weakness increases the level of unintended outcomes of state institutions, I suggest that we should not measure state weakness by those unintended outcomes.

4 It is worth noting that exceptions exist at both ends of the scale: the Chilean state, for example, has effective reach throughout essentially its entire territory, while the Haitian state's absence is equally ubiquitous.

5 It should be noted, however, that some aspects of stateness (such as legitimacy) are not territorial in character. For example, the failure of the Peruvian state to effectively respond to the Shining Path insurgency in the 1980s affected the reach of democratic institutions into certain locales (ie elections were cancelled in municipalities directly affected by the conflict) but affected the legitimacy of the state throughout the country. 
Given the importance of the spatial unevenness of state capacity, it is critical to incorporate this important aspect of Latin American stateness into our definition and measurement scheme. There are three approaches we might consider for doing so. The first would be a local level one: we could take as the unit of analysis the local context, and assess state capacity in that neighborhood or district or town. This would have the advantage of being sensitive to local levels of stateness, but would fail to take into account anything about the characteristics of the national state except for those that directly have a concrete impact at the local level. By neglecting the national state completely, this approach would provide too limited a window into the 'stateness' we want to investigate.

A second approach could assess state capacity at a national level. We would simply measure the extent of reach of each aspect of the state over territory. Thus, to provide a very much over-simplified example, we could calculate that the state can extend its extractive capacity over territory including $90 \%$ of the population, provide security to $80 \%$, and so forth. ${ }^{6}$ One commonly deployed type of data for this analysis is the International Road Federation's road density measure (Herbst, 2000; Hanson and Sigman, 2011). This approach would sacrifice information about the depth of the state's reach into any given location to focus on the extent of its span over space. Yet this would still be an improvement over the simple scoring of each case in a manner that is insensitive to reach over territory (as in standard measures of army size, GDP per capita, etc.).

A third approach could seek to combine the strengths of these two. We could then calculate something like a mean score for the level of state capacity in a country, and a parameter that captures the extent of variation from that mean level (unevenness) across the country as a whole. This approach would have the advantage of generating a meaningful measure of national-level state capacity, while being more sensitive to the level of stateness in any particular setting. While sensitive to local variation, however, the national-level score generated would lack any information about the state's power in any particular location, since this location-specific information is aggregated to develop an overall figure for variation across territory. This last approach is the one pursued in this paper, since it incorporates information about the overall level of stateness in the country along with information about the extent to which that stateness is present in any given local context. In so doing, I hope to balance the importance of national-level and local-level manifestations of the state.

\section{Measurement in the Latin American Context}

A single measure of state capacity that is intended to apply across all time and space will be un-necessarily blunt. As an analogy, consider for example the Alvarez et. al. measurement scheme for regime type, which simply uses the presence of competitive elections for chief executive and legislature to code for the presence or absence of democracy (Alvarez et. al., 1996). While this measurement is useful for broad analysis of 
a large number of countries across large swaths of time -indeed it can be used to code all countries in the world since 1850, as Boix and Rosato have done- it fails to capture more subtle differences among regimes. In part this is due to its dichotmous nature, but in part this is simply due to the bluntness of the coding rules. When focusing on a smaller set of countries that are relatively similar, we can attune our measurement strategy to develop a rubric that contains fine distinctions within the relevant portion of the scale, even if this implies sacrificing the ability to capture variation in portions of the scale where none of the countries fall.

The idea is to build a measurement scheme for state capacity that will be able to distinguish among the various levels of imperfect stateness in Latin America, not to simply identify the well-understood fact that Latin American cases in general fall short of the stateness observed in (for example) European states. ${ }^{7}$ We want, in other words, to be able to distinguish between the level of stateness in contemporary Mexico and that in Colombia in the 1980s, and between Haiti and Honduras today, rather than to label all four of these as relatively weak states by contemporary global standards, and in so doing we should be willing to sacrifice the ability to identify fine distinctions between the capacity of the Swedish and Norwegian states, or between the states in Niger and Chad. One way to assure this outcome from our measurement scheme is to ensure that the cutpoints we develop for coding each measure are nuanced enough at the appropriate point on the scale to translate small distinctions on each dimension into distinct scores.

\section{Existing Measures}

Hanson and Sigman (2011, Table Six) refer to 33 existing indices of state capacity, as well as thirteen commonly used proxies for some element of the concept. Mata and Ziata (2009) refer to eleven additional, freely available indices for state weakness. Given the plethora of existing measures, one must be able to identify a compelling reason for introducing a new one. This section takes stock of existing approaches, and identifies some gaps that I propose to fill with the scheme developed below.

\section{Existing Approaches to State Weakness}

A veritable industry of indices measuring state weakness, state failure, and state fragility has cropped up in recent years. Yet there are three reasons to be cautious about using these to measure state capacity in contemporary Latin America. First, as Mata and Ziata (2009: 35) point out, "most fragility indices barely satisfy scientific standards". They rely on expert assessments, fail to make careful choices about aggregation, and provide little information about scoring. Second, most fragility indices are based on overly broad conceptions of state fragility. For example, the Failed States Index incorporates civilian control of the military, the impunity of security forces, state-sponsored violence, and youth unemployment

7 We want, in other words, to move beyond Centeno (2002) to develop a measurement scheme that captures variation within Latin America. 
into its conceptualization scheme (ibid.: 55). Similarly, the World Governance Indicators incorporate regime dynamics by calculating political instability (which is commonly used as an indicator of state fragility) as the risk of destabilization or overthrow of a government. Third, and most importantly, state capacity is conceptually distinct from state fragility or failure. Rather than measuring capacity as the absence of weakness, we should begin from capacity itself; a strategy that has the advantage of measuring capacity independent of its effects (Hanson and Sigman, 2011: 15-16; Soifer, 2008).

\section{Existing Approaches to State Capacity}

Scholars have used a wide range of proxies for state capacity, ranging from GDP per capita (Fearon and Laitin, 2003) to road density (Herbst, 2000) and census administration (Soifer, forthcoming). Most common, however, are various measures of the state's ability to extract revenue-scholars use many different operationalizations of the state's extractive power as measures of overall capacity. These commonly used measures, however, suffer from several fundamental problems. First are issues of concept-measure validity. Most measures only consider one dimension of state capacity- yet it is not clear that (for example) extraction, coercion, policing, and administration co-vary closely enough to justify using a measure of one as an overall indicator of capacity. Hanson and Sigman (2011) discuss this issue in detail. Carrying out a factor analysis of existing approaches, they identify six analytically distinct aspects of state capacity. Three relate to extraction, one to coercion, one to administrative quality, and the last to state 'reach.' Thus, single dimension measures of state capacity are inappropriate for attempts to measure state capacity in general terms.

Second, none of these measures incorporate the uneven reach of the state across territory. Despite the fact that Hanson and Sigman identify state 'reach' as an analytically distinct dimension of state capacity, and that scholarship in a wide range of substantive fields has identified the reach of the state as crucial, we still rely on national-level indicators to measure state capacity.

\section{The Way Forward}

Hanson and Sigman usefully build on existing scholarship to identify the core dimensions of state capacity: extraction, coercion, and administration, and to highlight the importance of reach across territory. The next step is to build a measurement scheme that takes these insights into account and provides a way to apply them.

\section{Measuring State Capacity in Latin America}

\section{Conceptualization}

The measurement of state capacity must begin with an explicit identification of the constituent dimensions of the concept. Like most other scholars, I frame state capacity as consisting of three core dimensions: administration of some very basic set of services, security provision, and extraction. 
While provision of public goods is an essential component of the definition of state capacity, as discussed above, we should not define stateness by the scope of types of provision in which the state is engaged. Instead, we should assess the extent of the state's ability to administer the provision of some very basic set of services. Here I seek, however, to separate the ability to administer from the services themselves. Yet the most important public good the state provides is security. Our conceptualization of state capacity, then, must incorporate security as a second component. Because these depend on access to resources, we should also consider as a third component the ability of the state to extract. Extraction is a particularly direct evaluation of Mann's concept of the ability of the state to impose its chosen policies on society. It also allows us to see in our measure of state capacity the difference between states that depend on external flows or rents for governance, and those that draw upon a relationship of control and legitimacy constructed with citizens. (Levi, 1989; Lieberman, 2002) Thus, the overall assessment of state capacity incorporates three elements: security, administration, and extraction.

Before proceeding to develop indicators for each of these dimensions, we must consider how to aggregate these dimensions -how our scores on each of these three elements should be combined into a single score for capacity. I suggest that for a state to have capacity, it must be able to perform all three of the functions described above. Thus, I define all three as necessary for a state to have capacity-for example, I would want to consider a state that could provide security and basic services but not extract resources to be weak. Following Goertz (2006) we should therefore use the product of the values for the three measures to assess the overall score for capacity. Using the product, rather than an additive or averaging measure, prevents high scores on one dimension of state capacity for substituting for low scores on another- this mode of aggregation treats each dimension as a necessary component of state capacity.

\section{The Indicator Level}

Above I identified three distinct dimensions of state capacity: security, service provision, and extraction. My task in this section is to identify a basket of indicators that can be used to assess each of these. Unlike the dimension level, these indicators are intended to be substitutable, and are to be combined by averaging. This is partly because the multiple indicators on each dimension tap a similar aspect of state capacity, and partly to allow users of this measurement scheme to cope with data limitations.

\section{Security}

Security is difficult to measure directly, since short of ethnographic or survey research, we can most easily assess it by seeing where it is absent. We need to be careful here to assess state capacity to provide security independent of the presence of challengers to its rule. Although challengers may emerge (and persist) as a consequence of state weakness, their presence should not be included in our measurement scheme for state 
weakness. I propose three indicators of the security dimension of state capacity: violent crime, lynching rates, and the use of private security.

The first indicator I propose is the violent crime rate: though the causes of crime are of course more complex than state weakness, the presence of violent crime reflects the inability of the state to provide security. Despite difficulties in measurement of crime, it therefore acts as a useful (if imperfect) indicator of security. Given the imperfection and political manipulation of official crime statistics including murder rates, I propose to use a question from the LAPOP survey, which asks respondents whether they have been a victim of a crime. ${ }^{8}$

Second, I propose to look at lynching rates: as Goldstein (2003) and Godoy (2006) among others have shown, the phenomenon of lynching or 'street justice' is also a direct reflection of the weakness of the state, since in the insecurity that results, communities come to rely on non-state forms of 'justice' against criminals. While the availability of consistent cross-national data will be a problem, the rate of lynching serves as a second indicator of the security dimension of stateness.

The use of private security acts as the third indicator of the security dimension. It reflects the perception of societal actors about the extent of threat to their safety. ${ }^{9}$ A similar measure has been proposed to assess the extent of security in Afghanistan, though given the security climate there and the ubiquity of private protection, an indicator of whether state officials were willing to sleep in the districts they served was more useful in capturing variation in perceived security (Kilcullen, 2009).

I propose that in combination, these three indicators capture the extent of security provided by the state. These are particularly appropriate indicators in a context of high inequality, which characterizes the whole region, since inequality is a necessary but insufficient condition for all these processes ${ }^{10}$ (Caldeira, 2000). Given that these measures all capture similar aspects of security, I propose standardizing measures for each, and averaging the three to score the level of security for a given political jurisdiction. Scores for each jurisdiction, weighted for population and area, can be combined to generate a national-level score for this aspect of stateness, adjusted for uneven reach through the procedure described below.

\section{Administration}

The challenge here is to choose the right aspects of administration to measure. One that is fairly demanding or advanced, on which all Latin American countries will score fairly low, will occlude some of the cross-national variation. Therefore we would not

\footnotetext{
8 I propose using answers to question \#VIC1EXTA, listed on p. 6 of the 2010 LAPOP questionnaire. This question asks how many times the respondent has been victim of a crime in the last 12 months.

9 More accurately, this indicator only provides information about the perceptions of those actors who can afford to hire security. This is an important limitation to this indicator, but not one that I believe undermines its utility. 
want to use a measure like broadband internet provision here. ${ }^{11}$ Nor would we want to use a measure like the primary school provision, since variation is truncated by the overall success of its provision. I propose three measures that might be useful to assess the administrative capacity of the minimal state.

The first is census administration. Here my focus is not on the presence or absence of a census at a national level, but on the extent to which any given community is included in census counts. To take an example, the 1902 Peruvian educational census contains an explicit discussion of the geographic scope of data collection, describing missingness at the provincial, district, and community level (Soifer, 2013). Overall, administrators noted that the census covered $90 \%$ of the country's school age population, and $75 \%$ of its territory. One province (the Amazonian province of Ucayali) was neglected entirely, as were fifteen other districts. At the community level, more than $80 \%$ of the country's 745 districts are missing data for at least one community. We can use this information to identify the places where this face of the state is powerful (where full data is collected), limited (where data is partial), and absent (where no data is collected). Thus, one can review a given iteration of a country's census for partial and incomplete data collection to get a sense of the reach of the state administrative apparatus.

The state's ability to register its citizens is a second measure of administrative capacity. Here we can look at national identity registration and (where voting is mandatory) voter registration. Where are there gaps in these types of registration? Who is excluded? This reflects the inability of the state to collect basic information about citizens or to provide basic services. In Peru, for example, the 2006 election revealed systematic gaps in voter registration - residents of Amazonian regions were far more likely to be unable to participate in the elections because they lacked national identification cards. ${ }^{12}$ The LAPOP survey, which asks respondents about whether they are registered voters, is a useful source for data here. ${ }^{13}$

A third measure of service provision, which taps an aspect of public goods that states have long provided in Latin America, is vaccination. Vaccines, despite the fact that they are administered individually, are best seen as a public good because of the fact that their administration protects whole populations from infection. And indeed they are seen as such by public health establishments throughout Latin America - even governments not terribly concerned with service provision have been careful to implement vaccination

11 Note, too, that broadband internet has another problem we might want to avoid: it is usually provided by a private actor rather than by the state. We want to ensure that the measure of provision we choose is one that is provided by the state rather than by a private actor (firm or NGO) or an international donor. The eradication of polio in Nigeria, for example, would not necessarily reflect an increase in the capacity of that country's state. Similarly, studies of $19^{\text {th }}$ century state capacity should consider whether railroad density is an appropriate meaure given that railroads were often constructed by private actors.

12 For information on this problem, see Maxwell Cameron's essay at blogs.ubc.ca/peru/2006/06/09/ elections-democracy-and-the-state/

13 Here I propose to use question \#VB1, listed on p.13 of the 2010 LAPOP questionnaire, which asks respondents whether they are registered to vote or have a national identity card (depending on the country.) 
programs. Thus, the rates of vaccination of populations (by location) can be used as a measure of service provision. ${ }^{14}$

Thus, I propose three indicators of state administrative capacity, each of which is to be assessed at the level of the smallest political jurisdiction for which data is available. Standardized values for each of these indicators can be averaged, and then combined via the population and territory weighting and the reach-adjusted scoring approach described below into a national score for provision.

\section{Extraction}

To explore the ability of the state to impose upon the population it claims to rule, I propose three measures. Two relate to taxation, and calculated as national-level scores. The third reflects the ability of the state to regulate economic activity, and can be measured in a manner that captures territorial variation.

First, I propose to develop a measure that captures the mix of taxes on which the state depends for revenue. The portfolio of taxes on which a state relies reflects its capacity in two ways. First, taxes vary in their spatial distribution of incidence: those that can be collected in a small number of central locations require a more skeletal administrative apparatus than those that require the distribution of agents throughout the territory. ${ }^{15}$ Thus, a state that relies heavily on customs duties -collected only at major ports of entry and exit- requires little in terms of extractive capacity throughout the vast remainder of its national territory, while the taxation of domestic commerce, wealth, or income, requires the state to have a much greater reach. Second, taxes vary in the difficulty of assessment and collection required to extract revenue. For example, it is easier (though less precise) to impose a tax based on the area of land owned than a tax on the value of land, or to impose customs duties by weight rather than by value as in Colombia during parts of the $19^{\text {th }}$ century. (Rosenthal, 2012; Scott, 1998) Thus, I propose to use the percentage of revenue generated from income and wealth taxes divided by the percentage of revenue generated from customs and resource rents as the first measure of state extractive capacity. A higher reliance on direct taxes will cause a state to be scored higher on capacity; a high reliance on trade taxes and resource rents will have the opposite effect. ${ }^{16}$

Second, I propose to use the level of taxation to examine the extractive dimension of state power. Here the quantity of interest is the level of imposition by the state on its

This requires identifying which vaccines are provided by government agencies, and which by the World Bank and other development associations. In other words, we want to measure not the percentage of the population that has been vaccinated, but the percentage of the population that was vaccinated by state agencies, whether national or local.

15 Thus even though this is a national-level indicator, its calculation incorporates some information about the spatial reach of the state.

16 One concern here is that this measure would generate similar scores for states that collect high levels of both taxes and those that collect low levels of both. In practice, given the very weak correlations between trade and income taxes, this is not as big a problem as it might seem in theory (Hanson and Sigman, 2011, Table 5). 
citizens. ${ }^{17}$ Duties on the exports of raw materials, monopoly profits, and customs duties are excluded because they are not imposed directly on the population. The numerator is calculated by summing taxes on income, property, and wealth, sales taxes, inheritance taxes, and various fees for service and permits. By dividing this quantity by the size of the population, we can get a measure of the average amount extracted by the state per capita. This amount can be calculated at the national level, and compared across time or across countries with appropriate adjustments for inflation and purchasing power where possible. By combining information on the tax burden with information on the broader set of revenue sources of the state, we can get a nuanced picture of its power to tax.

A limitation of both of these measures of extractive capacity is that they are shaped by preferences over taxation in addition to the capacity to tax: while capacity may act as an upper bound on both the types of tax collected and the tax burden, a government may choose not to tax to the extent it could. For example, the drastic reduction of taxes with the neoliberal turn in Chile after 1973 did not derive from the massive weakening of the state's capacity to extract. Instead, it was driven by policy preferences. We therefore need to complement them with a measure of state extractive capacity that is independent of these preferences. (Soifer, forthcoming).

Thus, a third measure of extraction must be added. Given that the first two measures provide no information on the presence of the state in any given community, we should choose an indicator that can be operationalized at the local level. The third indicator of extractive capacity I propose is the share of population working in the formal sector of the economy. This captures the ability of the state to regulate and tax economic activity. ${ }^{18}$ It can be calculated at the local level, adjusted for reach as discussed below, and combined with the tax indicators above. Thus, the overall score for extractive capacity will be the average of the three indicators, adjusted for the reach of the formal economy over population and territory.

\section{Addressing Unevenness}

The last concern in developing a measure of state capacity is to consider how to incorporate the importance of the state's reach into the measurement scheme; how to adjust for reach over population and territory. Taking reach into account is what distinguishes the measure developed in this paper from existing measurement schemes.

The state's reach is uneven in two ways: across territory, and across society. Yet a measure of unevenness that simply uses the full national territory as a denominator would generate low scores for countries (like Brazil) that have large and relatively unpopulated regions. We may think that is appropriate for a country like Brazil, given that the state's weakness (in terms of the inability to enforce environmental protection legislation) is one

17 A helpful discussion of how to choose among the myriad options for operationalizing this concept appears in Lieberman (2002).

18 Some alternatives to consider here are the share of economic transactions that are formalized. Barzel (2002) uses this to measure what he calls the scope of the state), and the percentage of housing that is titled. 
of the factors underlying the deforestation of the Amazon. But given that much scholarly interest in the state centers on the interplay between state and society, we may want to include populated territory alone in our measurement of unevenness.

My proposal is a compromise between spatial and social measures - I propose to weight the territorial reach of the state by the proportion of national population in a given location. This rewards states (by generating a higher score for stateness) for effectively penetrating areas with large populations, while also taking into account their ability to reach into relatively unpopulated rural areas to impose control over territory. Thus, the definition hews close to Michael Mann's dual emphasis on reaching over territory to penetrate society in his definition of infrastructural power.

To adjust for the reach of the state where applicable (as described above, two of the indicators of extractive capacity I propose are space-invariant) I propose the following approach: I weight local jurisdiction ("district") level data for the territorial size and population of the local jurisdiction as a share of the national (Population*Area), and then sum the weighted district-level scores to calculate a national score. This score is then divided by the variance across district level scores, so that as variance (which represents the uneven reach of this dimension of the state) rises, the score for the dimension of stateness is reduced. This method provides a reach-adjusted, population and territory weighted, measure of stateness. The overall measurement strategy is depicted in Figure 1, below and explained in more detail in the notes accompanying the figure.

Figure 1: Measuring State Capacity ${ }^{19}$

\begin{tabular}{llll}
\hline \multicolumn{3}{c}{ State Capacity } \\
\hline Dimensions: & \multicolumn{1}{c}{ Security } & \multicolumn{1}{c}{ Administration } & \multicolumn{1}{c}{ Extraction } \\
\hline Indicators: & Violent Crime Rate & Census Administration & Direct Taxes/Indirect Taxes \\
& Lynching Rate & $\begin{array}{l}\text { National Identity Card } \\
\text { Registration }\end{array}$ & Direct Taxes per Capita \\
& $\begin{array}{l}\text { Private Security per } \\
\text { capita }\end{array}$ & Vaccination Rates & $\begin{array}{l}\text { Share of working } \\
\text { population in formal sector }\end{array}$ \\
\hline
\end{tabular}




\section{CONCLUSION}

This paper has developed a measurement scheme for state capacity in contemporary Latin America. It builds on existing approaches by maintaining the salience of extraction, security provision, and administration. It incorporates both the overall level of these dimensions of state strength and the spatial and social unevenness of the state, and yet does so without giving up on the national state to focus on the local presence of the state in studies of single communities. In so doing, it moves beyond both a capabilities-centered approach to state capacity such as that of Goodwin (1999) or Fearon and Laitin (2003), and a local 'weight of the state' approach as taken by many anthropologists to develop a measure that hews uniquely closely to Michael Mann's definition of infraastructural power as the ability of the state to reach across territory into society and effectively implement its chosen policies. There are barriers to measurement of the indicators proposed above, including the challenges of choosing comparable measures across countries, and finding accurate data on the sizes of subnational jurisdictions. These barriers are far from insurmountable, particularly given that the measure is designed for application to the relatively small number of countries in Latin America across relatively recent periods of time.

It is worth, in closing, being explicit about the bounded applicability of this measurement scheme. I have opted to maximize precision and the careful description of variation within a set of cases that are (in world-historical terms) marked by broadly similar levels of state capacity. Rather than facilitating the comparison of contemporary Peru to Sweden, Swaziland, or $19^{\text {th }}$ century Switzerland, the measure developed here allows for careful comparison among countries in the region, using a holistic scoring for state capacity that incorporates all relevant dimensions in a single scheme. By contrast, most other measurement schemes (see Hanson and Sigman, 2011, and Mata and Ziata, 2009) are designed to be general and to allow such broad comparisons over space and time. That choice, while appropriate for some research needs, carries severe costs in the validity and reliability of measurement, sacrificing the ability to capture the multifaceted and uneven nature of state capacity. My hope is that other scholars who are interested in measurement and comparison among a set of fairly similar cases will also pause before downloading and blindly using an existing dataset, and consider instead designing a data collection and measurement scheme for their set of cases; one that strives to best capture the aspects of state capacity that are most appropriate for their context.

\section{REFERENCES}

Alvarez, Michael, José Cheibub, Fernando Limongi and Adam Przeworski. 1996. "Classifying Political Regimes". Studies in Comparative International Development 31 (2): 3-36.

Barzel, Yoram. 2002. A Theory of the State: Economic Rights, Legal Rights, and the Scope of the State. Cambridge: Cambridge University Press.

Bowman, Kirk et al. 2005. "Measuring Political Democracy". Comparative Political Studies 38 (8 [October]): 939-970. 
Caldeira, Teresa. 2000. City of Walls: Crime, Segregation, and Citizenship in Sao Paulo. Berkeley and Los Angeles: University of California Press.

Centeno, Miguel. 2002. Blood and Debt: War and the Nation State in Latin America. Pennsylvania: Penn State University Press.

Fearon, James D. and David D. Laitin. 2003. "Ethniaty, Insurgency, and Civil War". American Political Science Review 97 (1): 75-90.

Fukuyama, Francis. 2004. State building: Governance and World Order in the $21^{\text {st }}$ Century. Ithaca, NY: Cornell University Press.

Godoy, Angelina. 2006. Popular Injustice: Violence, Community and the Law in Latin America. Stanford: Stanford University Press.

Goertz, Gary. 2006. Social Science Concepts. New Jersey: Princeton University Press.

Goldstein, Daniel. 2003. "In Our Own Hands: Lynching, Justice, and the Law in Bolivia". American Ethnologist 30 (1 [February]): 22-43.

Goodwin, Jeff. 1999. No Other Way Out. Cambridge: Cambridge University Press.

Hanson, Jonathan K. and Rachel Sigman. 2011. "Measuring state capacity: Assessing and testing the options". Paper presented at APSA.

Kilcullen, David. 2009. "Measuring Progress in Afghanistan" (Kabul) http:/ / humanterrainsystem.army. $\mathrm{mil} / \mathrm{htsDocs}$.aspx

Lange, Matthew. 2009. Lineages of Despotism and Development. Chicago: University of Chicago Press.

Levi, Margaret. 1989. Of Rule and Revenue. Berkeley and California: University of California Press.

Lieberman, Evan. 2002. "Taxation Data as indicators of state-society relations: possibilities and pitfalls in cross-national research". Studies in Comparative International Development 36 (4): 89-115.

Lieberman, Evan. 2003. Race and Regionalism in the Politics of Taxation in Brazil and South Africa. Cambridge: Cambridge University Press.

Mann, Michael. 1984. "The Autonomous Power of the State: Its Origins, Mechanisms, and Results". European Journal of Sociology 25 (2): 185-213.

Mata, Javier F. and Sebastian Ziata. 2009. Users' Guide on Measuring Fragility. Bonn and Oslo: German Development Institute and United Nations Development Programme.

O'Donnell, Guillermo. 1993. "On the State, Democratization, and Some Conceptual Problems". World Development 21 (8): 1355-1369.

Rosenthal, Joshua. 2012. Salt and the Colombian State: Local Society and Regional Monopoly in Boyacá 18211900. Pittsburgh: University of Pittsburgh Press.

Scott, James C. 1998. Seeing Like a State. New York: Yale University Press.

Soifer, Hillel and Matthias vom Hau. 2008. "Unpacking the 'Strength' of the State: the Utility of Infrastructural Power". Studies in Comparative International Development 43 (3-4): 219-230.

Soifer, Hillel. 2013. "Elite Preferences, Administrative Institutions, and Educational Development During Peru's República Aristocrática 1895-1919". In State and Nation Making in Latin America and Spain: Republics of the Possible. Cambridge: Cambridge University Press.

Soifer, Hillel. Forthcoming. "State Power and the Economic Origins of Democracy". Studies in Comparative International Development.

Thoumi, Francisco. 1995. Political Economy and Illegal Drugs in Colombia. Boulder, CO: Lynne Rienner Publishers Inc.

Yashar, Deborah. 2005. Contesting Citizenship. New York: Cambridge University Press.

Hillel David Soifer is Assistant Professor of Political Science at Temple University. PhD in Government, Harvard University. His main lines of research are in comparative politics, Latin American politics, and qualitative methodology.

E-mail: hsoifer@temple.edu 